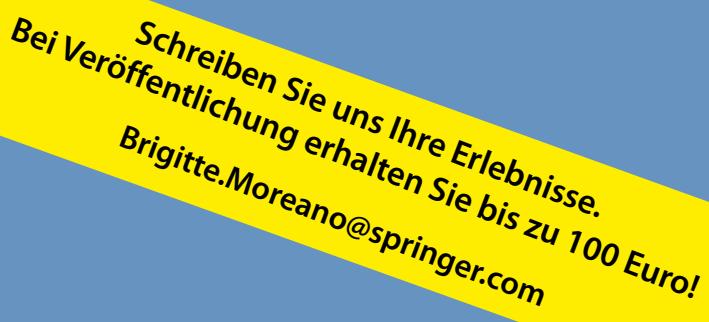

\begin{abstract}
Ärztliche Erfahrung beschränkt sich nicht auf medizinisches Fachwissen. Sie entsteht auch aus den mehr oder minder alltäglichen, heiter, ärgerlich oder nachdenklich stimmenden Erlebnissen mit Patienten, Kollegen und Mitarbeitern. Senden Sie uns Ihre Geschichte an: Brigitte.Moreano@springer.com. Für jeden veröffentlichten Text erhalten Sie bis zu 100 Euro.
\end{abstract}

\title{
Notfallgebühr im Glas versenkt
}

- Dass es nur eine Minute dauert, um die Praxisgebühr/Notfallgebühr für die Krankenkasse einzuziehen, können nur Gesundheitsminister glauben. Jeder Arzt kennt zahlreiche Gegenbeispiele.

So habe ich einmal im ärztlichen Notdienst einen ca. 45-jährigen Mann besucht, der Oberbauchschmerzen angab. Sein Äußeres, seine Äußerungen und herumstehende Flaschen deuteten darauf hin, dass er Alkoholiker war. Die Untersuchung zeigte ein weiches Abdomen mit leichtem Druckschmerz im Epigastrium bei ansonsten unauffälligem Befund. Unter der Verdachtsdiagnose Gastritis erhielt er ein Magenschutzpräparat und die Aufforderung den Hausarzt in den folgenden Tagen wieder einmal aufzusuchen.

Dann kam es, wie es kommen musste: Der Patient hatte angeblich kein Geld, um

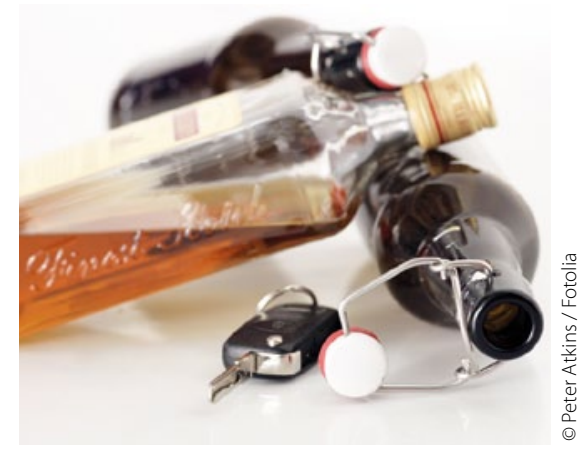

Für den Doktor ist kein Geld mehr da.

die Notfallgebühr zu bezahlen. Wahrscheinlich hätte er sich als Arbeitsloser nur von der Zuzahlung befreien lassen müssen, hatte sich aber nicht darum gekümmert. Und das wenige Bare, das er erhielt, hatte er regelmäßig in flüssige Kost umgesetzt. Das sei aber kein Problem, eröffnete er mir, denn nächste Woche komme seine alte Mutter zu Besuch und von der erhalte er dann die $10 €$, die er dann sofort an mich weiterleite. Ich fragte, wie er das denn tun wolle, er habe ja meine Kontonummer gar nicht. Er würde mir das Geld entweder überweisen oder in meinen Briefkasten einwerfen.

Selbstverständlich kam das Geld weder in der folgenden Woche, noch im folgenden Monat oder im folgenden Jahr. Das ist zwar unverschämt, aber nicht schlimm. Schlimmer fand ich, dass ein Mittvierziger von seiner alten Mutter, die wahrscheinlich auch nur wenig Geld zur Verfügung hat, bei deren Besuch Geld für die Notfallgebühr abzockt und dieses dann in Alkohol umsetzt.

DR. MED. RaINER HAKIMI, STUtTGART •

\section{Notärztin auf Abwegen}

- Der mächtige neobarocke Bau der Poliklinik aus dem Jahr 1910 gehört zu den architektonischen Schmuckstücken des Münchner Klinikviertels. Wenn man das Hauptportal an der Pettenkoferstraße durchschreitet, gelangt man in die Eingangshalle, die von einem mächtigen Bogen von 13 Metern Spannweite überwölbt ist und von der aus sich nahezu drei Meter breite Treppenläufe zu beiden Seiten in den ersten Stock entwickeln. Die Treppen werden von einer Marmorbalustrade zur Halle hin begrenzt, an den Treppenanfängen finden sich ruhende Kinderfiguren in Marmor von Ernst Pfeiffer, die Decke ist stuckiert und an einer Wand hängt eine gewaltige Bronzetafel mit der Aufschrift:„Erbaut unter der Regierung S K Hoheit des Prinzregenten Luitpold des Königreichs Bayern Verweser MCMVII-MCMX".

Die Medizinische Poliklinik meldete in der Regel ihre wenigen Betten für akute Neuzugänge ab, was man sich in der VorDRG-Ära in einer Universitätsklinik einer Großstadt mit sehr vielen Krankenhäusern erlauben konnte. Gelegentlich verirrte sich aber doch ein Krankentransportwagen in unsere Klinik. Bei einem meiner Nacht- dienste kam gegen 22 Uhr eine junge Notärztin im orangefarbenen Anorak in Begleitung zweier Sanitäter mit einem liegenden Kranken in dieser Halle. Sie schien nicht in München studiert zu haben, da ihr beim Betreten dieses Ambientes vor Staunen fast der Kinnladen herunter fiel. Ihre rhetorische Frage: „Wo bin ich hier, in einer Klinik oder in einer Kirche?" zeugte zwar von wenig Kunstverständnis, ließ aber zumindest auf eine gewisse christliche Erziehung schließen.

Prof. Dr. MEd. H.-S. FÜESSL, HAAR = 